\title{
High rates and a healthy city
}

The year 1874 was a good one for the British city of Birmingham. Because of the entrepreneurial spirit of Joseph Chamberlain, the long awaited public health infrastructure was installed in the city-paid for from the profits of the recently municipalised gas works. It is the sort of civic story that ought to be recounted more often. At a time of renewed interest in public health it is instructive to look at the British experience at the end of the last century-a period when it was at the forefront of public health policy. Local government has come a long way from the heyday of municipal autonomy of the late 19th century, a period during which, despite increasing supervision from central government, there was a huge opportunity for creative projects that enriched urban life and, more significantly, improved the public health.

The formative British public health legislation, initiated by the Liverpool Sanatory Act of 1846 and culminating in the "great" Public Health Act of 1875, reflected the contemporary beliefs in what caused ill health and high death rates. ${ }^{1}$ A theory of disease transmission through "miasmas", gasses emitted from rotting refuse and sewage, translated into a predominantly sanitary and environmental programme of reforms. These focused on cleaning the public spaces in towns and cities, through the installation of waterworks, sewerage systems, refuse collection, street paving and washing. These infrastructures were invariably municipal - with earlier private waterworks succumbing to municipal buy outs when they failed to provide water "in the public interest".

However, the legislation during this 30 year period to 1875 was essentially permissive. Local authorities were usually not compelled to provide these systems, and in many towns there were active groups of residents who could put together a very convincing case for not making these sanitary reforms. Edwin Chadwick's revolutionary egg shaped sewers, new types of street paving, constant water supply and water closets were all ideas that had not been fully evaluated. Part of the opposition to these reforms was a reluctance to take on board advice, and in some cases inspection and coercion, from central government in London in an era when local autonomy was highly prized.

But it was often finance that prevented the immediate widespread adoption of sanitary reforms. The Public Health Act of 1847 made provision for raising funds to install waterworks, sewerage systems, and other infrastructure. This was to be done through levying a rate on the local property owners, the same principle that had been used successfully for many years to pay for the Poor Law. Once town councils had agreed that some improvements to their sanitary systems were needed, the usual course of action was to appoint a consultant civil engineer to make a survey and produce an estimated cost. In practice, the early projects from the 1840 s to the 1870 s frequently exceeded the estimates that had been sanctioned by the local councillors. There was little they could do-the construction of large schemes such as Rivington Pike waterworks for Liverpool, or the Longdendale waterworks for Manchester were still in a formative stage. The civil engineers who designed them were learning through experiment, which as Liverpool found to its cost, could go badly wrong. The cost of the schemes, often running into hundreds of thousands of pounds, was financed through raising loans on the security of the local rates. There was no state funding to subsidise the burden, or to assist places with low rateable values. The cost was born entirely locally. The repayment period was usually 30 years - more than an average life expectancy for a working class man in the 1850 s, but not long enough to prevent a noticeable strain on the municipal purse. ${ }^{2}$

The dilemma facing local authority councillors 100 years ago was thus: how to make the necessary improvements to the public health through building a proficient sanitary infrastructure but without increasing the rates and alienating the ratepayers who had voted them into office. Chamberlain's slogan "High Rates and a Healthy City" made his concerns explicit-better to pay for the preventive systems than to pay for the ill health that their absence may cause. Chamberlain, however, found ways around the problem. He appeased the ratepayers lobby by developing other municipal services to pay for public health projects. Gas works were only one of many profit generating ventures that British local authorities were engaged in by 1900-including tramways, electricity supply, markets and public baths and wash houses. More unusual trading activities adopted by some towns anxious to raise money included municipal bakeries, racecourses, and pawnshops. Some towns were more ambitious than others and some suffered for their zeal. One Mancunian ratepayer, angry at paying three times as much in rates as his London contemporary to cover the losses on the Manchester Ship Canal, told the council: "The State has scourged us with whips, but you have scourged us with scorpions".

By 1900 local authorities had expanded their portfolio of activities to provide not only public health services but also education, housing, and welfare. Much of this had been achieved by enthusiastic councillors with business acumen, who were anxious to develop a sense of civic pride in their home towns. Municipal service brought with it social status, and allowed local people with invaluable local knowledge to contribute to the planning and growth of their towns and cities. For this reason the town council chamber became the natural place in which to discuss public health policy.

This period at the end of the 19th century witnessed the creation for most urban areas of the sanitary infrastructure that is still in use today. With hindsight we should be more grateful than perhaps we are for the decisions made by councillors, pressed on them by novice public health professionals, and paid for by trusting local ratepayers. Their considerable personal investment for the sake of the public's health was not part of a simplistic whiggish progress to a healthy city, fashioned by central government. It was an intensely local battle that reflected local wealth, politics and importantly, pride in the health of the community. Perhaps it is these elements that need to be fostered for the public health of the new millennium.

SALLY SHEARD

Department of Public Health and School of History, University of Liverpool

1 Hamlin C, Sheard S. Revolutions in public health: 1848 and 1998? BMF 1998;317:587-91.

2 Millward R, Sheard S. The urban fiscal problem, 1870-1914: government expenditure and finance in England and Wales. Econommic History Review 1995;XLVIII:501-35. 